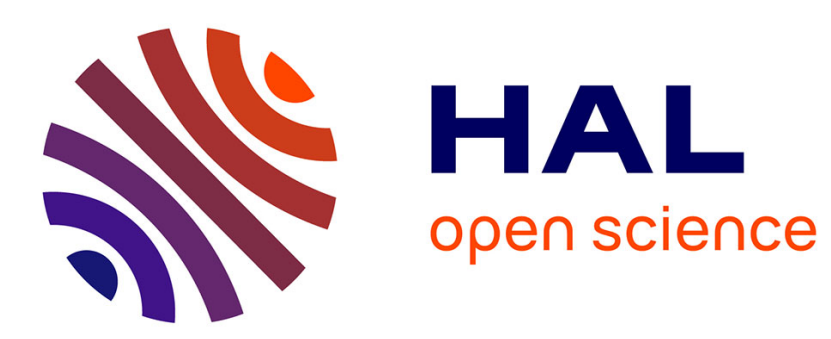

\title{
Alloying effects in self-assembled InAs/InP dots
}

J. Brault, Michel Gendry, G. Grenet, G. Hollinger, Y. Desieres, T. Benyattou

\section{To cite this version:}

J. Brault, Michel Gendry, G. Grenet, G. Hollinger, Y. Desieres, et al.. Alloying effects in self-assembled InAs/InP dots. Journal of Crystal Growth, 1999, 201, pp.1176 - 1179. 10.1016/S0022-0248(99)000202. hal-02194226

\section{HAL Id: hal-02194226 \\ https://hal.science/hal-02194226}

Submitted on 26 Jul 2019

HAL is a multi-disciplinary open access archive for the deposit and dissemination of scientific research documents, whether they are published or not. The documents may come from teaching and research institutions in France or abroad, or from public or private research centers.
L'archive ouverte pluridisciplinaire HAL, est destinée au dépôt et à la diffusion de documents scientifiques de niveau recherche, publiés ou non, émanant des établissements d'enseignement et de recherche français ou étrangers, des laboratoires publics ou privés. 


\title{
Alloying effects in self-assembled InAs/InP dots
}

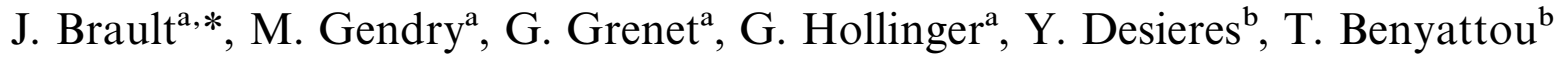 \\ ${ }^{a}$ Laboratoire d'Electronique-LEAME, UMR CNRS 5512, Ecole Centrale de Lyon, 36 Av G. de Collongue, 69131 Ecully Cedex, France \\ ${ }^{\mathrm{b}}$ Laboratoire de Physique de la Matière-LPM, UMR CNRS 5511, INSA de Lyon, Bat. 502, 69621 Villeurbanne Cedex, France
}

\begin{abstract}
We have studied the influence of alloying induced chemical exchange reactions on the formation of self-assembled InAs dots prepared on $\mathrm{InP}$ and $\mathrm{In}_{0.52} \mathrm{Al}_{0.48} \mathrm{As}$ buffers lattice-matched to $\mathrm{InP}(001)$. Atomic force microscopy and lowtemperature photoluminescence measurements have been used to characterize the dot properties. Strong differences in the islanding process are observed depending on the growth conditions and on the nature of the buffer layer. They are associated to variation in intermixing between the InAs deposit and the buffer layer. (C) 1999 Elsevier Science B.V. All rights reserved.
\end{abstract}

PACS: $81.15 . \mathrm{Hi} ;$ 68.35.Rh; 68.35.Dv

Keywords: Self-assembled dots; InAs/InP; Solid-source MBE; AFM; Photoluminescence; Alloying

\section{Introduction}

It is now well known that quantum wires or dots can be obtained using the Stransky-Krastanov growth mode of strained layers. However, for device application, their spatial self-organization as well as their size, shape and distribution uniformity remain a challenging prerequisite [1]. Recent works have shown that alloying effects such as surface segregation [2], spinodal decomposition [3], or chemical exchanges [4,5] can greatly influence the nanostructure properties. We have shown recently [6] that such alloying effects as well as buffer morphology can affect strongly the islanding

\footnotetext{
* Corresponding author. Tel.: + 33-047-2186086; fax: + 33047-8433593.

E-mail address: julien.brault@ec-lyon.fr (J. Brault)
}

process when "InAs" nanostructures are prepared on three different buffers, i.e., InP, InAlAs and InGaAs lattice-matched to $\operatorname{InP}(001)$. Both $3 \mathrm{D}$ morphology relaxation and chemical relaxation had to be taken into account to understand strain relaxation and dot formation. In this work, we concentrate on the InAs/InP system and we show that controlling the As-P chemical exchange reactions allow to modify strongly the spatial distribution and the size of the dots. A comparison is done with the InAs/InAlAs system where only III element alloying is possible.

\section{Experimental procedure}

The samples consist of $3 \mathrm{ML}$ of InAs (just above the critical threshold of the $2 \mathrm{D} / 3 \mathrm{D}$ growth mode 
Table 1

Buffer growth conditions and dot characteristics for InAs/InP and InAs/InAlAs systems. $N / D$ represents the ratio between the total dot volume $(N)$ and the deposited InAs amount $(D)$

\begin{tabular}{|c|c|c|c|c|c|c|c|c|}
\hline Sample & Buffer & $\begin{array}{l}\text { Growth } \\
\text { temperature } \\
\left({ }^{\circ} \mathrm{C}\right)\end{array}$ & $\begin{array}{l}\text { As stabilization } \\
\text { time (s) }\end{array}$ & $\begin{array}{l}\text { Dot length } \\
(\AA)\end{array}$ & $\begin{array}{l}\text { Dot width } \\
(\AA)\end{array}$ & $\begin{array}{l}\text { Dot height } \\
\text { (̊) }\end{array}$ & $\begin{array}{l}\text { Dot density } \\
\left(\text { per } \mathrm{cm}^{2}\right)\end{array}$ & $N / D$ \\
\hline A & InP & 480 & 10 & 1100 & 600 & 160 & $5 \times 10^{9}$ & 2.5 \\
\hline B & $\operatorname{InP}$ & 480 & 600 & 900 & 500 & 70 & $1 \times 10^{10}$ & 2.5 \\
\hline $\mathrm{C}$ & InP & 450 & 10 & 800 & 550 & 50 & $5 \times 10^{9}$ & 0.75 \\
\hline $\mathrm{D}$ & InAlAs & 525 & - & 550 & 300 & 15 & $8 \times 10^{10}$ & 0.65 \\
\hline
\end{tabular}

Note: $P_{\mathrm{As}} \sim 5 \times 10^{-6}$ Torr and InAs growth rate is $0.2 \mathrm{ML} / \mathrm{s}$ for all samples.

transition) deposited by solid-source molecular beam epitaxy (MBE) on $4000 \AA \operatorname{InP}$ and $\mathrm{In}_{0.52} \mathrm{Al}_{0.48} \mathrm{As}$ buffers. We used atomic force microscopy (AFM) to investigate the dot size and distribution. $4 \mathrm{~K}$ photoluminescence (PL) allowed to study the optical properties of the dots after capping with InP and InAlAs, respectively. Growth parameters and AFM characteristics are collected in Table 1 .

\section{A comparison between InAs/InP and InAs/InAlAs}

Fig. 1 shows AFM images and the corresponding PL spectra for $3 \mathrm{ML}$ of InAs deposited on InP (sample A) and InAlAs (sample D), using the standard growth temperature of $480^{\circ} \mathrm{C}$ and $525^{\circ} \mathrm{C}$, respectively. The corresponding dot characteristics are presented in Table 1. Strong differences are observed between the two systems. Small dots are obtained for InAs/InAlAs whereas large dots are formed on InP. When comparing the total dot volume $(N)$ to the deposited InAs amount $(D)$, an $N / D$ ratio of 0.65 is found for InAs/InAlAs dots while an $N / D$ ratio of 2.5 is found for InAs/InP dots. This indicates that dots are made of $\operatorname{InAs}_{1-x} \mathrm{P}_{x}$ alloy in the InAs/InP system. This behavior is understood when comparing the mixing enthalpies $\Delta H_{\mathrm{m}}=x(1-x) \Omega$ of $\operatorname{InAs}_{1-x} \mathrm{P}_{x}$ and $\mathrm{In}_{1-x} \mathrm{Al}_{x} \mathrm{As}$, where $\Omega$ is the interaction parameter reflecting the energy excess associated with bond distorsion. $\Omega$ is equal to $720 \mathrm{cal} / \mathrm{mol}$ for InAsP and to $3600 \mathrm{cal} / \mathrm{mol}$ for InAlAs. The easier alloying for InAs/InP explains why the largest dots are ob- served on InP, taking into account that alloying allows to relax part of the total strain energy. For InAlAs, InAs surface segregation [7] and spinodal decomposition [8] prevent $\mathrm{In}_{1-x} \mathrm{Al}_{x} \mathrm{As}$ alloy formation in the dots during the islanding process.

PL measurements shown in Fig. 1 confirmed that only InAs/InAlAs behave as quantum dots. The multiline PL spectrum reported in Fig. 1c for InAlAs can be fitted with six gaussian components (FWHM $\sim 50 \mathrm{meV}$ ). When the excitation power is increased, the low energy components begin to saturate whereas the high energy ones continue to increase. We attribute these components to a mixture of quantum dot excited states [9] and monolayer fluctuations of the dot height [10]. For high excitation power the lower quantum dot levels saturate as expected. The lateral quantum confinement is thus evidenced. Fig. 1a shows the PL spectrum in the case of an InP matrix (sample A). It consists in a discrete series of at least seven lines between 0.8 and $1.3 \mathrm{eV}(\mathrm{FWHM}=25 \mathrm{meV})$ at $200 \mu \mathrm{W}$. A slight increase of the FWHM is detected when the excitation power is increased, the peak shape remaining almost the same. Such peaks have been attributed to monolayer fluctuations of the dot height [10]. Because of the large lateral size of the dots $(100 \mathrm{~nm})$, they behave like quantum wells. The broadening observed with an excitation power increase is attributed to band filling effects.

\section{Controlling InAs/InP}

The above results have shown that the lateral size of the InAs/InP islands has to be reduced in 

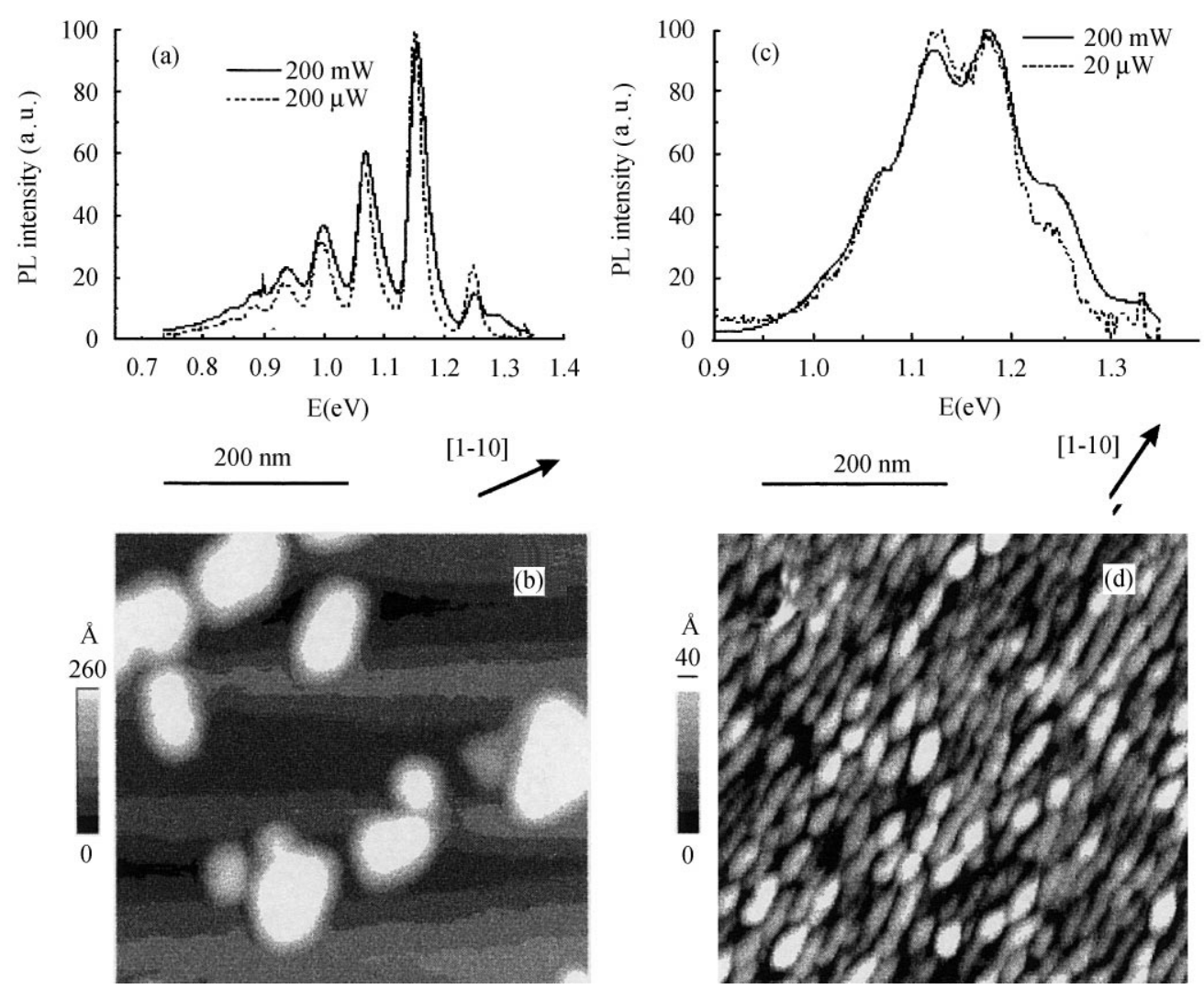

Fig. 1. Photoluminescence spectra at $4 \mathrm{~K}$ of InAs dots embedded in: (a) an InP matrix and (c) an $\operatorname{In}_{0.52} \mathrm{Al}_{0.48} \mathrm{As}$ matrix. Typical $\mathrm{AFM}$ images of the dots for: (b) InAs/InP and (d) InAs/InAlAs.

order to achieve a quantum dot behavior similar to InAs/InAlAs. This was performed by modifying the As-P chemical exchange at different stages of the islanding process: (i) during the arsenic-stabilization of the InP surface, (ii) during the InAs deposition.

As the InP buffer is exposed to arsenic overpressure before InAs deposition, arsenic atoms are known to replace the outgoing phosphorus [11]. Previous XPS results [11] have shown that annealing of InP under arsenic leads to about 1.25-1.5 arsenic equivalent monolayers in the $450-500^{\circ} \mathrm{C}$ range. Table 1 and Fig. 2 show that when increasing the arsenic-stabilization time from $10 \mathrm{~s}$ (sample A) to $10 \mathrm{~min}$ (sample B), before InAs deposition, the dot density is two times higher and the dot heights are two times smaller whereas the dot distribution is much more homogeneous. In particular, the dot alignment related to the buffer surface morphology (large terraces with simple and double steps) disappears. In contrast, the total dot volume remains constant $(N / D \sim 2.5)$. This clearly indicates that if some $\mathrm{V}$-element alloying exists already prior to the InAs deposition, most of As-P exchanges are strain induced and happen during the InAs 2D growth step. $N / D \sim 2.5$ indicates that about 8 equivalent ML are involved in the dots. Taking into account that only $\sim 4 \mathrm{ML}$ of InAs are available to built the dots, this suggests that the dots are made of $\operatorname{InAs}_{1-x} \mathrm{P}_{x}$ with $x \sim 0.5$.

For $10 \mathrm{~s}$ arsenic-stabilization, it is expected that the "InAsP" surface layer is chemically inhomogeneous (equilibrium is not reached) which could explain an inhomogeneous nucleation of dots. Increasing the buffer surface chemical homogeneity (with a 10 min treatment) should lead to 

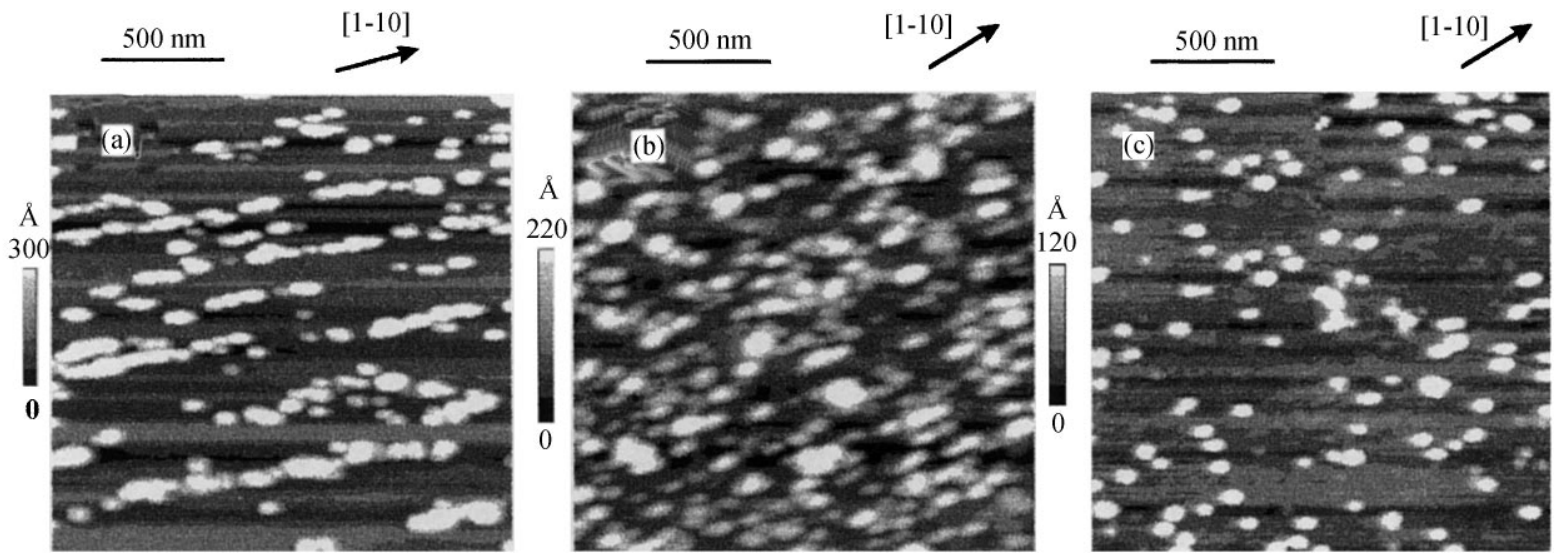

Fig. 2. Typical AFM images of the dots in the case of an InP buffer: (a) sample A, (b) sample B, (c) sample C. See Table 1 .

a more homogeneous lateral dot distribution as observed. However, a higher roughness of the buffer surface due to the 10 min treatment, leading to a higher density of nucleation sites, could also explain this more homogeneous distribution.

Finally, an interesting result is observed when decreasing the process temperature from $480^{\circ} \mathrm{C}$ to $450^{\circ} \mathrm{C}$ (sample C), still using a $10 \mathrm{~s}$ arsenic-stabilization step. The dot density is identical to that of sample A. In contrast, the dots are two times smaller with a less pronounced alignment and elongation along the $\left[\begin{array}{lll}1 & 1 & 0\end{array}\right]$ direction and $N / D \sim 0.75$. Obviously, decreasing the growth temperature lowers the adatom mobility during the $3 \mathrm{D}$ growth but also the efficiency of the As-P chemical exchange leading to a more As-rich composition for the dots.

\section{Conclusion}

We have shown that alloying effects associated to chemical relaxation can influence strongly the size and composition of self-assembled InAs/InP dots. Limiting the As-P chemical exchange should allow to prepare small quantum dots in the
InAs/InP system for operation at $1.55 \mu \mathrm{m}$. The density of dots appears to be controlled by the availability of nucleation sites.

\section{References}

[1] D. Bimberg, M. Grundmann N.N. Ledentsov, MRS Bull. 23 (1998) 31, and references therein.

[2] N. Grandjean, J. Massies, O. Tottereau, Phys. Rev. B 55 (1997) R10189.

[3] H.J. Lee, H. Ryu, S. Nahm, J. Crystal Growth 182 (1997) 292.

[4] N. Carlsson, T. Junno, L. Montelius, M.-E. Pistol, L. Samuelson, W. Seifert, J. Crystal Growth 191 (1998) 347.

[5] B. Wang, F. Zhao, Y. Peng, Z. Jin, Y. Li, S. Liu, Appl. Phys. Lett. 72 (1998) 2433.

[6] J. Brault, M. Gendry, G. Grenet, G. Hollinger, Y. Desières, T. Benyattou, Appl. Phys. Lett. 73 (1998) 2932.

[7] G. Grenet, E. Bergignat, M. Gendry, M. Lapeyrade, G. Hollinger, Surface Sci. 352 (1996) 734.

[8] G. Grenet, M. Gendry, M. Oustric, Y. Robach, L. Porte, G. Hollinger, O. Marty, M. Pitaval, C. Priester, Appl. Surf. Sci. 123/124 (1998) 324.

[9] K. Mukai, N. Ohtsuka, H. Shoji, M. Sugara, Appl. Phys. Lett. 68 (1996) 3013.

[10] J.F. Carlin, R. Houdré, A. Rudra, M. Ilegems, Appl. Phys. Lett. 59 (1991) 3018.

[11] E. Bergignat, M. Gendry, G. Hollinger, G. Grenet, Phys. Rev. B 49 (1994) 13542. 